\title{
Variations de la teneur en glucides de l'érable à sucre
}

\author{
J.P. Renaud ${ }^{1}$ et Y. Mauffette ${ }^{2}$ \\ 1 Centre de Recherche Acéricole, Ministère de l'Agriculture des Pêcheries et de l'Alimentation du \\ Québec, St-Hyacinthe, Québec, J2S-8E3, et \\ 2 Groupe de Recherche en Ecologie Forestière, U.Q.A.M., Québec, H3C-3P8, Canada
}

\section{Introduction}

Les glucides constituent la principale forme de réserve énergétique des arbres (Kramer et Kozlowski, 1979). Bien que l'étude des variations saisonnières, principalement de l'amidon, a fait l'objet de plusieurs travaux (Jones et Bradlee, 1933; Wargo, 1978; Bonicel et al., 1987), peu d'études ont portées sur la variation des teneurs en glucides en fonction des différents organes et de l'état physiologique de l'arbre.

Cette étude vise à déterminer les variations de la teneur en amidon et en sucres solubles dans l'érable à sucre (Acer saccharum Marsh.) en fonction de la saison, de l'organe étudié, du diamètre et de l'éloignement des racines à partir du tronc.

\section{Matériel et Méthodes}

\section{Site et échantillonnage}

En 1987, 62 arbres ont été échantillonnés à l'érablière du Centre de Recherche acéricole du M.A.P.A.Q., située à $200 \mathrm{~km}$ au nord-est de Montréal. Le diamètre de ces arbres à hauteur de poitrine variait entre 17 et $67 \mathrm{~cm}$ et leur hauteur entre 14 et $28 \mathrm{~m}$.

Un sous-échantillonnage de 7 arbres a permis de déterminer la variabilité de la teneur en sucres pour les échantillons de racine et de tronc, récoltés en mai et en octobre. Les racines ont été récoltées selon leur diamètre : $A$, moins de $1 \mathrm{~cm}$; $B$, de 1 à $2 \mathrm{~cm}$ et $C$, de 2 à 4 $\mathrm{cm}$. La distance entre les racines prélevées et le tronc était de $0,6,1,2$ et $2,1 \mathrm{~m}$. Les échantillons de tronc ont été prélevés à $30 \mathrm{~cm}$ du sol.

A l'automne, les réserves amylacées de 55 arbres ont été déterminées. Deux racines de $0,5 \mathrm{à} 1 \mathrm{~cm}$ de diamètre ont été récoltées sur chaque arbre dont la condition de la cime (i.e., pourcentage de feuillage manquant) avait été préalablement évaluée en juin.

\section{Méthode analytique}

Immédiatement après leur prélèvement, les échantillons ont été nettoyés et conservés à $-20^{\circ} \mathrm{C}$ avant d'être lyophylisés. Le matériel lyophylisé a été broyé à sec $(40 \mathrm{mesh})$. L'extraction a été faite dans du méthanol:chloroforme: eau (12:5:3).

Les sucres solubles de la fraction aqueuse de l'extrait ont été analysés par chromatographie liquide à haute pression (HPLC). Le résidu a été traité avec de l'amyloglucosidase (EC 3.2.1.3, Sigma Chemical Co., St. Louis, MO, U.S.A.) selon Haissig et Dickson (1979). Le glucose libéré a été déterminé par HPLC. Les résultats obtenus ont été exprimés en pourcentage de poids sec.

\section{Résultats}

La teneur en sucres solubles est, indépendamment de la période de l'année, plus 

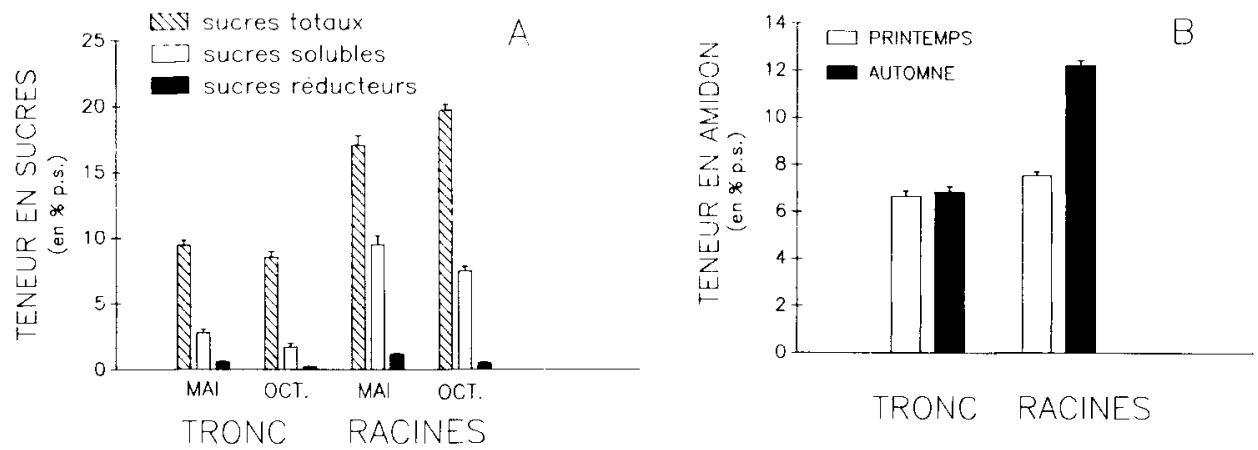

Fig. 1. Variation de la teneur: (A) en sucres; (B) en amidon, en fonction de la période de l'année et de l'organe échantillonné. Sucres réducteurs: glucose + fructose; sucres solubles: sucres réducteurs + saccharose et mannitol; sucres totaux: sucres solubles + amidon. Les barres verticales représentent l'erreur standard.

élevée dans les racines que dans le tronc (Fig. 1A). Par contre, la teneur en amidon est significativement plus élevée (Anova: $P<0,01)$ dans les racines à l'automne qu'au printemps (Fig. 1B).

En automne, la teneur en amidon varie selon le diamètre des racines (Anova: $P$ $<0,05$ ) (Fig. 2A). En effet, les racines de 2 à $4 \mathrm{~cm}$ de diamètre contiennent moins d'amidon que celles de moins de $1 \mathrm{~cm}$. La teneur en saccharose pour sa part, augmente avec l'éloignement des racines du tronc (Fig. 2B).
On observe une relation négative ( $P$ $\left.<0,01, R^{2}=0,25\right)$ entre la condition de la cime d'un érable et ses réserves amylacées racinaires (Fig. 3 ).

\section{Discussion et Conclusion}

Les résultats obtenus indiquent que la teneur en glucides de l'érable à sucre varie suivant la période de l'année et l'organe étudié (i.e., tronc ou racines). Le

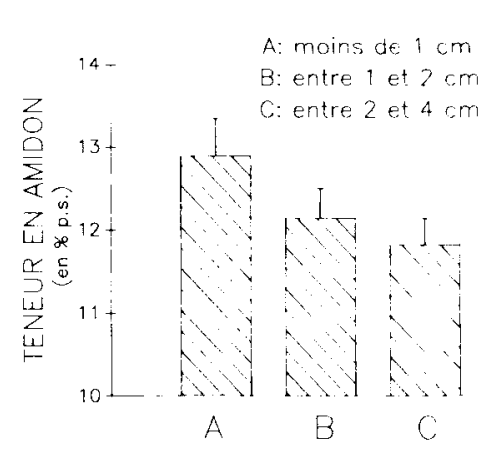

DIAMETRE DES RACINES

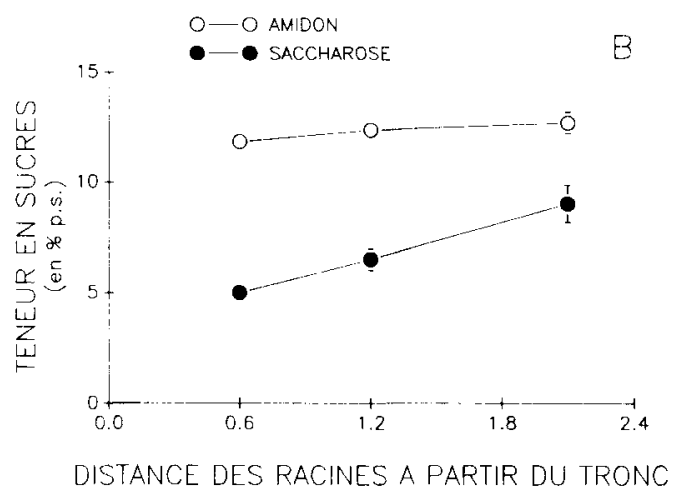

Fig. 2. Variation de la teneur en sucres en fonction: (A) du diamètre des racines et (B) de la distance (en $\mathrm{m}$ ) des racines à partir du tronc, en automne. Les barres verticales représentent l'erreur standard. 


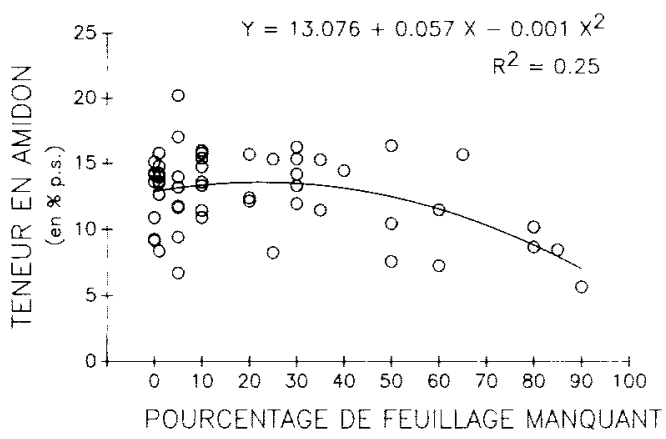

Fig. 3. Variation de la teneur en amidon des racines récoltées en automne en fonction du pourcentage de feuillage manquant de la cime.

diamètre des racines a un effet sur la teneur en amidon; ceci est aussi observé chez le chêne (Wargo, 1976). De plus on remarque que la condition de la cime joue un rôle important dans la formation des réserves. II est donc très important de tenir compte de ces variations lors d'études comparatives portant sur les réserves de l'érable à sucre.

Des recherches actuellement en cours visent à établir une relation entre la croissance d'un érable à sucre dépérissant et ses réserves glucidiques.

\section{Remerciements}

Les auteurs tiennent à remercier MM. Guy Boudreault, Marcel Breton et $M^{\text {ma }}$ Jacqueline Beaupré pour leur assistance technique.

\section{Références}

Bonicel A., Haddad G. \& Gagnaire J. (1987) Seasonal variations of starch and major soluble sugars in the different organs of young poplars. Plant Physiol. Biochem. 25, 451-459

Haissig B.E. \& Dickson R.E. (1979) Starch measurement in plant tissue using enzymatic hydrolysis. Physiol. Plant. 47, 151-157

Jones C.H. \& Bradlee J.L. (1933) The carbohydrate content of the maple tree. Vt. Agric. Exp. Stn. Bull. 358, pp. 147

Kramer P.J. \& Kozlowski T.T. (1979) In: Physiology of Woody Plants. Academic Press, New York, pp. 811

Wargo P.M. (1976) Variation of starch content among and within roots of red and white oak trees. For. Sci. 22, 468-471

Wargo P.M. (1978) Judging vigor of deciduous hardwoods. in: Gypsy Moth Handbook. USDA Agriculture, Information Bulletin no. 418, pp. 315 